\title{
СТОИМОСТНОЙ АСПЕКТ НМЦК (НАЧАЛЬНОЙ МАКСИМАЛЬНОЙ ЦЕНЫ КОНТРАКТА) В ЗАКУПОЧНОЙ ДЕЯТЕЛЬНОСТИ
}

\author{
(C) 2019 Ровбель Ростислав Леонидович \\ Заместитель губернатора Смоленской области \\ 214008, г. Смоленск, площадь Ленина, 1 \\ E-mail: rovbel_rl@admin-smolensk.ru
}

В статье проведено исследование механизма формирования и использования НМЦК в закупочной деятельности. Автор предлагает выделить стоимостной аспект НМЦК на основе существующих видов стоимости в оценочной деятельности. Актуальность темы заключается в предположении автора о том, что повышение эффективности системы закупок зависит от величины стоимостной характеристики НМЦК.

Ключевые слова: закупочная деятельность, начальная максимальная цена контракта (НМЦК), рыночная стоимость.

Система закупок является сложным и многоступенчатым механизмом, который объединяет в себе множество участников, представленных государственными и частными агентами. Несмотря на функционирование системы закупок в условиях рыночной экономики, процедуры проведения закупок по контрактной системе накладывают ряд ограничений на участников закупок, которые связаны с их выполнением следующих функций: планирования, мониторинга, контроля исполнения. Сложившаяся практика жесткого регламентирования отдельных процессов, связанных с работой государственных структур и компаний с государственным участием, является особенностью исторического развития экономики государственного сектора России [2]. Основной задачей законодательного регламентирования сферы закупок является выполнение функций мониторинга и контроля над расходом бюджетных средств, а также повышение эффективности бюджетных расходов и борьба с коррупционными рисками. Рынок государственных закупок в России составляет более четверти ВВП страны, поэтому организация эффективной и прозрачной и системы закупок является ключевым фактором развития экономики государства [3].

Сфера законодательного регулирования государственных закупок претерпела и продолжает претерпевать значительное число изменений, что создает определенные трудности в связи с изменениями и ростом требований к квалификации лиц, ответственных за проведение закупок и участие в них. Изменения в законодательстве во многом положительно сказались

на сфере закупок в части уменьшения числа прямых нарушений, однако несовершенство системы закупок, главным образом проявляется в части ограничения конкуренции в процедуре закупок, в том числе через механизм определения НМЦК, что подтверждается практикой решения арбитражных споров, например:

- Решение Карельского УФАС по делу № 04-18/322-2017 (https://fas.gov.ru/documents/ 601872);

- Определение Верховного Суда Российской Федерации от 08.04.2016 № 308-КГ16-1857 (http://vsrf.ru/stor_pdf_ec.php?id=1430100);

- Решение Арбитражного суда Амурской области от 21 апреля 2015 г. по делу № A04-1548/2015 (http://sudact.ru/arbitral/doc/ vfL7LfKuEHHl/) [4].

Приведенные выше случаи не являются единственными в судебной практике и практике антимонопольных органов. Подобные прецеденты наглядно демонстрируют наличие серьезных возможностей в манипуляции результатами закупок и реализации коррупционных схем через механизм определения НМЦК, которые позволяют делать вывод о неэффективности российского механизма закупок. Описанные примеры сводят к необходимости внимательного рассмотрения вопроса существования параметра НМЦК, его роли в механизме закупок.

По мнению Автора, НМЦК является необходимым показателем для сферы закупок, однако необходимо пересмотреть условия ее определения. Ключевым вопросом в сфере организации системы закупок является вопрос расчета НМЦК. Данный показатель можно рассматривать не 
только с точки зрения стоимостной характеристики контракта, но и как инструмент для оценки эффективности закупки, поэтому она важна не только для участников закупки, но и для контролирующих служб.

Начальная (максимальная) цена контракта выражается денежными средствами, которые Заказчик готов заплатить Исполнителю для осуществления закупок. Следует отметить, что Исполнителями являются юридические лица, не только предоставляющие свои услуги исключительно на рынке закупок, но и осуществляющие свою деятельность в рыночных условиях. Таким образом, если цена контракта будет ниже рыночной цены, то Исполнителю не будет финансово выгодно осуществлять работы. В том случае, если цена будет слишком завышена, то нарушится принцип эффективности использования бюджетных средств (Бюджетный кодекс Российской Федерации от 31.07.1998 № 145 - ФЗ ст.34).

НМЦК определяется пятью методами в соответствии со ст.22 Ф3 № 44 «О контрактной системе в сфере закупок товаров, работ, услуг, для обеспечения государственных и муниципальных нужд» от 05.04.2013. Среди методов определения НМЦК выделяют следующие: метод сопоставимых рыночных цен (анализа рынка); нормативный метод; тарифный метод; проектно-сметный метод; затратный метод. Проведем анализ сущности и характеристик, присущих НМЦК при ее определении в рамках того или иного метода.

В рамках метода сопоставимых рыночных цен (анализа рынка) НМЦК формируется на основе цен на объект закупки, установленных рынком. В случае отсутствия идентичных товаров, работ или услуг, НМЦК формируется на основе цен на однородные товары, работы или услуги. В данном случае НМЦК принимается аналогом рыночной стоимости, рассчитанной сравнительным подходом в рамках оценочной деятельности. Согласно Федеральному стандарту оценки (ФСО № 1) «Общие понятие оценки, подходы и требования к проведению оценки»), утвержденному приказом Минэкономразвития России от 20.05.2015 г. № 297, п.12, сравнительный подход состоит в расчете стоимости объекта оценки путем поиска, сопоставления и (в случае необходимости) корректировки цен на аналогичные объекты, представленные на открытом рынке. Информационной базой для обоих расчетов служат данные рынка, которые могут быть получены как из единой информационной системы (базы объявлений в интернете, журналах), так и путем запроса у конкретных организаций (в случае если объект/предмет закупки является специализированным, например будки рентгеновские аппараты в аэропортах). Из вышеизложенного следует, что величина, формируемая в рамках метода сопоставимых рыночных цен и сравнительного подхода к оценке, обладает одинаковой сущностью.

Нормативный метод определения НМЦК заключается в расчете цены контракта на основе существующих нормативно-правовых актов или локальных требований в государственной структуре, определяющих количественные и качественные характеристики предмета закупок. Тарифный метод при расчете НМЦК имеет небольшую схожесть с нормативным методом, поскольку тарифный метод основан на определении НМЦК в соответствии с тарифами на цены товаров, работ и услуг, регулируемых государством. При расчете нормативным методом на величину НМЦК будет оказывать влияние изменение лимитов затрат, методики их расчета и иные факторы, которые находятся под контролем соответствующего органа исполнительной власти, устанавливающего нормативы на определенный вид товара, работы или услуги. Поскольку и в тарифном методе величины тарифов регламентируются органами государственной власти, то как при нормативном, так и при тарифном методе НМЦК, по сути, не зависит от участников закупочной деятельности, а находится под контролем государства [4].

Проектно-сметный метод при формировании НМЦК, согласно п.9. ст. 22, Ф3-44, рекомендуется использовать только при заключении договора с единственным поставщиком. Таким образом, с одной стороны, это позволит Заказчику выбрать наиболее объемный список работ по доступным ценам, с другой же,- ведет к вероятности возникновения недостоверной информации от Исполнителя о предполагаемой стоимости материалов или сырья.

В том случае, если не представляется возможным использовать ни один из вышеперечисленных методов формирования НМЦК, Заказчику следует использовать затратный метод. Затратный метод основан на определении совокупного перечня затрат, увеличенного на прибыль предпринимателя - прибыль, которую получит непосредственно Исполнитель, и значе- 
ние которой должна отражать текущая ситуация на рынке (иными словами, «рыночная наценка» на товар или услуги).

Рассмотрев методы определения НМЦК, перейдем к выявлению «стоимостной» сущности НМЦК в разрезе оценочной деятельности.

Федеральный стандарт оценочной деятельности (ФСО № 2 «Цель оценки и виды стоимости»), утвержденный приказом Минэкономразвития России от 20.05.2015 г. № 298, определяет следующие виды стоимостей: рыночную, инвестиционную, ликвидационную и кадастровую. Поскольку исследование Автора направлено на внедрение инструментария оценочной деятельности в институт закупок, рассмотрим данные понятие и выявим какой вид стоимости наиболее отражает сущность НМЦК.

Кадастровая стоимость (используется в качестве базы налогообложения при расчете налога на имущество) представляет собой наиболее вероятную цену объекта недвижимости без учета его обременений и ограничений и определяется методами массовой оценки. Поскольку предметами закупки выступают, в большинстве своем, объекты движимого имущества данное понятие, по мнению. Автора, никоим образом не применимо к НМЦК [1].

Ликвидационная стоимость - стоимость, при которой объект отчуждается на рынке в условиях ускоренной и вынужденной продажи. Однако процедура закупок не предусматривает «вынужденное» оказание услуг Исполнителем Заказчику, таким образом, данный вид стоимости не коррелируется с понятием НМЦК.

Инвестиционная стоимость - стоимость, определяемая для конкретного инвестора или группы лиц, не отражающая учет возможности реализации объекта на открытом рынке. Однако процедуры закупок являются открытыми торгами, и такие методы определения НМЦК, как метод анализа рынка, проектно-сметный метод, затратный метод, предполагают формирование НМЦК на основе данных рынка (прибыль предпринимателя - в затратном методе, цены на аналогичные товары/работы/услуги у поставщиков - в методе анализа рынка и т.д.). Иными словами, инвестиционной составляющей НМЦК, прямо отражающей понятие «инвестиции», не представляется возможным выявить.

Остается последний вид стоимости, который, по мнению Автора, находит свои черты в НМЦК,- рыночная стоимость. Проводя парал- лели с методами определения НМЦК, в каждом из них есть рыночная составляющая:

- метод сопоставимых рыночных цен строится на информации о рыночных ценах на идентичные товары, работы и услуги;

- нормативный и тарифный метод определения НМЦК представляется возможным сопоставить с рыночной стоимостью через призму расчета права пользования на условиях аренды нормативным методом (в таком случае рыночная стоимость рассчитывается с учетом установленных органов местного самоуправления порядков определения размеров арендной платы);

- проектно-сметный и затратный методы коррелируются с понятием «рыночная стоимость» через один из подходов к определению рыночной стоимости, а именно: затратный. Затратный подход при определении рыночной стоимости рассчитывается на основе затрат на воспроизводство или замещение объекта.

Так как система закупок является по своей сути искусственным механизмом, необходимо минимизировать в ней существующие пробелы и возможности реализации коррупционных схем. Рассматривая показатель НМЦК, как стоимостную характеристику, необходимо отметить близость его сущности к понятию «рыночной стоимости» несмотря на то, что НМЦК определяется закупщиком, ее основная составляющая рыночная информация.

Рыночная стоимость определяется на основе анализа спроса и предложения на рынке, в практике оценочной деятельности ключевым аспектом выделяют независимость специалиста, который производит расчет и обоснование величины рыночной стоимости. По мнению Автора, формальная привязка НМЦК к рыночной стоимости, даже подкрепленной результатами анализа рынка, не позволяет НМЦК достичь необходимого уровня объективности и обоснованности без кардинального изменения условий ее определения. Еще одним существенным изменением в подходе к определению НМЦК послужит тот факт, что будет упрощен механизм определения параметров эквивалентности товаров, и цена перестанет являться решающим фактором выбора поставщика, так как параметр соотношения цена/качество будет определяться в ходе обоснования НМЦК специалистом на основании детального подхода к полноценному анализу характеристик закупаемого товара. Цена не может быть использована в качестве 
определяющего критерия выбора поставщика, поскольку сравнение только по критерию цены не объективно.

Рассматривая НМЦК как показатель, который имеет значение для функций мониторинга и контроля, можно отметить, что предлагаемые преобразования смогут быть применены и в процессе постзакупочного мониторинга и проверок, например, со стороны контрольных органов, иными словами, возможно проведение разъяснений о соотношении затрат с реальной необходимостью и сопоставление объемов закупки в денежном выражении с рыночной стоимостью того объема продукции.

При рассмотрении недостатков показателя НМЦК и способов их нивелирования необходимо отметить также тот факт, что, если детальнее рассмотреть практику оценочной деятельности, можно найти варианты «модернизации» показателя НМЦК. Например, в практике оценочной деятельности существует возможность определить обоснованные анализом рынка интервалы изменения рыночной стоимости, как в сторону понижения, так и в сторону увеличения, что, по мнению автора, позволит объективно выявлять и предотвращать попытки демпинга или даже стратегий по завышению цен, как в описанном выше случае в практике Верховного Суда Российской Федерации от 08.04.2016 № 308-КГ161857 (http://vsrf.ru/stor_pdf_ec.php?id=1430100) [5]. Определение интервала рыночной стоимости применительно к показателю НМЦК добавит гибкости системе закупок за счет понимания участниками закупки рыночной конъюнктуры цен предложений на рынке.

Таким образом, рыночная стоимость - наиболее вероятная цена, при которой объект может быть отчужден на открытом рынке в условиях, когда присутствует конкуренция, а стороны осведомлены об условиях сделки, и отсутствует влияние каких-либо чрезвычайных условий на цену, лежит в понятии НМЦК.

Корректное определение сущности НМЦК и факторов, которые оказывают на нее влияние, позволит повысить эффективность и справедливость процедуры закупки в целом, а также будет способствовать корректному формированию цены контракта, которая будет соответствовать действительным ценам на рынке.

\section{Библиографический список}

1. Бакулина А.А. Ровбель Р.Л. Интеграция инструментов института оценки в процедуры обоснования начальной (максимальной) цены контракта в закупочной деятельности // Стратегические решения и риск-менеджмент. 2018. № 2 (105) С.70-75.

2. Белякова Е.П. Правовые формы планирования закупок товаров, работ и услуг для государственных нужд // Электронный вестник Ростовского социально-экономического института. 2016. № 3. С. 16-29.

3. Смотрицкая И.И., Шувалов С.С. Развитие института публичных закупок (к формированию новой модели контрактной системы закупок) // Экономические и социальные перемены: факты, тенденции, прогноз. 2017. № 5 (53). С. 99-114.

4. Нэгл Томас, Холден Рид К. Стратегия и тактика ценообразования. Руководство для принятия решений, приносящих прибыль. Санкт-Петербург. 2011. С. 544.

5. Федотова М.А., Бакулина А.А. Проблемы оценки стоимости активов промышленных предприятий в условиях экономического кризиса // Известия высших учебных заведений. Технология текстильной промышленности. . 2018. № 1 (373) С.24-26. 